\title{
LA AXIOLOGÍA JURÍDICA SEGÚN JORGE MILLAS ${ }^{1}$
}

\author{
Juan O. Cofré Lagos \\ Universidad Austral de Chile \\ jcofre@uach.cl \\ Carlos Isler Soto \\ Universidad Bernardo O’Higgins \\ Universidad Diego Portales \\ carlos_isler@yahoo.com
}

\begin{abstract}
Resumen / Abstract
En este trabajo esperamos describir las ideas fundamentales que constituyen el sustrato iusfilosófico de la axiología jurídica de Jorge Millas. En primer lugar expondremos sinópticamente las claves de la filosofía del derecho que desarrolla el pensador chileno en sus obras dedicadas a ese tema, incluyendo su concepción de la filosofía en general $(\S 1)$, y de la ciencia del derecho, en particular ( 2 ). En segundo término, mostraremos los supuestos epistemológicos de su filosofía del derecho (§3), y su consiguiente concepción de la esencia del derecho (\$4), de la norma jurídica (\$5) y el fundamento de ésta, y la doctrina axiológica que Jorge Millas elabora a partir de la relación y distinción entre las categorías gnoseológicas de "ser" y "deber ser" (\$6), para concluir con un análisis crítico que muestra las fortalezas y debilidades de la doctrina iusfilosófica de este autor chileno ( $\S 7$ y 8$)$.
\end{abstract}

Palabras clave: Jorge Millas, axiología jurídica, positivismo jurídico, intuicionismo husserliano, apriorismo kantiano.

THE JURIDICAL AXIOLOGY OF JORGE MILLAS

In this paper, we try to expose the fundamental ideas at the basis of Jorge Millas'axiology. First, we will expose synoptically the core of the legal philosophy that the Chilean thinker develops on his works on the subject, including his conception about philosophy in general (\$1), and about legal science in particular (\$2). Secondly, we will expose the epistemological suppositions of his legal philosophy (\$3), and his consequent conception of law's essence (\$4), the legal rule (\$5) and its foundation, and the axiological theory that Millas develops on the basis of the distinction and relationship between "is" and "ought" (\$6). We conclude with a critical analysis that pretends to expose the strengths and weaknesses of the legal theory of this Chilean author ( $\$ 7$ and 8).

KEY WORDS: Jorge Millas, legal axiology, legal positivism, Husserlian intuitionism, Kantian apriorism.

Este trabajo es parte de las investigaciones del Proyecto Fondecyt Nº1090535, "La filosofia jurídica de Millas: aportes relevantes". 


\section{Idea de la filosofía de Jorge Millas}

$\mathbb{R A}$ Visto que la filosofía jurídica de este pensador ha caído en el olvido en la cultura jurídica chilena contemporánea, y puesto que Millas despliega su filosofía del derecho a partir de una sólida concepción filosófica, parece prudente y necesario comenzar por mostrar en qué consiste su idea de filosofía en general.

Tres propiedades caracterizan en lo esencial la filosofía de este iusfilósofo: apriorismo, idealismo e intuicionismo. Es decir, su filosofía se inscribe fundamentalmente en el kantismo, por una parte, y en la filosofía fenomenológica alemana contemporánea, por otra. Según nuestro autor, la filosofía consiste en el esfuerzo racional de la inteligencia de llevar sus exigencias de comprensión de la realidad al límite. Una verdadera filosofía es un modelo de pensar de manera general y universal el ser y el deber ser, en sus diversas manifestaciones ideales o existenciales. A diferencia de las ciencias particulares o regionales (como las ciencias positivas), la filosofía aspira a un saber totalizador que sea capaz de explicar las cosas y los sucesos no en tanto cosas y sucesos, sino en tanto son o deben serlo. Este ejercicio racional de la inteligencia en el límite de sus posibilidades implica, también, la necesidad ineludible de fundamentar sus nociones y principios esenciales y, además, de construir explicaciones coordinadas de modo tal que vayan constituyendo sistemas explicativos que, a su vez, sean susceptibles de conectarse con otros sistemas mediante estrictas regularidades formales de las leyes de la racionalidad. Toda filosofía es, pues, un saber de fundamentos, una disciplina basada en las leyes más estrictas del pensamiento racional. De ahí, pues, que Millas pueda decir que la filosofía es un saber auto y toto fundante, es decir, que requiere pensarse a sí mismo y, al mismo tiempo, dotar de una base gnoseológica y epistemológica sólida los conocimientos filosóficos y no filosóficos que deben, en último término, dar cuenta de la verdad, sea ésta universal o regional. Así, la filosofía es fundamento de la filosofía del derecho, y la filosofía del derecho, a su vez debe, entre sus tareas, entregar la fundamentación de las ciencias jurídicas o dogmáticas en general.

En síntesis, tal como él mismo lo expone ${ }^{2}$ no es posible clarificar adecuadamente el concepto de filosofía del derecho, sino a partir del concepto de filosofía mismo y esto, porque, según él, la filosofía del derecho es, antes que ciencia jurídica, disciplina filosófica lo que, a su turno, da origen a dos consecuencias:

i) Que sus posibilidades cognoscitivas están dadas por las posibilidades del saber filosófico y,

ii) Que la filosofía del derecho es un sector de la filosofía en general.

2 Cfr. Millas 2012, II. 1. Este libro está constituido de capítulos y parágrafos. Se citará precisamente de esa manera. Por ejemplo: III. 3, lo que quiere decir: Capítulo III, Parágrafo 3. 
Y, si es así, entonces resulta natural que a partir de las grandes regiones de la filosofía -ontología, metafísica, gnoseología, lógica y metodología, y axiología- se fundan también la ontología o metafísica jurídica, la gnoseología jurídica, la lógica y metodología del derecho, y la axiología jurídica.

\section{Idea de ciencia del derecho}

No le compete al matemático necesariamente el estudio de la naturaleza de los números, así como no le compete al científico del derecho el estudio de la naturaleza, límites y posibilidades de su conocimiento positivo. En cambio, en ello reside precisamente una de las misiones más importante de la filosofía. La filosofía, como se ha dicho, debe dotar de fundamento y sentido el saber de estas ciencias particulares. Y tratándose de cuestiones jurídicas, la filosofía del derecho está llamada a explicar de qué ha de ocuparse realmente la ciencia jurídica si quiere ser rigurosamente ciencia. Si se pregunta por el objetivo de esta ciencia, todo el mundo estará de acuerdo en que su objeto de estudio es el derecho. Pero Millas observa, como lo han visto a lo largo de la historia muchos pensadores, que el acuerdo de los juristas es nada más que nominal, porque una vez que se entra a explicar qué se entiende por "derecho", las respuestas suelen ser totalmente diferentes y hasta incompatibles. Para unos el derecho es ciencia de hechos sociales, para otros es ciencia de normas positivas que entran en relación con las realidades humanas, para otros aún el derecho es ciencia de principios naturales, racionalmente captados, y sobre los cuales, y en armonía con ellos, el derecho positivo debe construir sus leyes.

Millas comienza por distinguir, lo que no es trivial, el derecho como disciplina racional y científica, del derecho como objeto de estudio de esta disciplina. Obviamente son cosas muy distintas. Según él, las ciencias del derecho deben ser radicalmente distinguidas y separadas de las ciencias de la naturaleza e, incluso, de las ciencias sociales que trabajan describiendo el mundo. Las ciencias jurídicas, son, nos dice, demostrativas, al modo de la matemática o de la lógica. Esta idea es de raigambre fenomenológica. Husserl sostiene en sus Investigaciones Lógicas que el resultado de sus indagaciones, relativo a la obtención de una nueva ciencia puramente teórica, "constituye el fundamento más importante de todo arte del conocimiento científico y posee el carácter de una ciencia a priori y puramente demostrativa" (Husserl 1982, vol. 1, 38), con lo cual, sostiene, se consolida la idea kantiana de un saber verdaderamente científico, es decir, que no depende de la experiencia, aunque se refiera siempre a ella.

Bien. ¿Cuál es, entonces, de acuerdo con esta concepción filosófica, el verdadero objeto de estudio de las ciencias jurídicas, como, por ejemplo, la dogmática civil, constitucional, penal, administrativa, etc.? De ninguna manera los hechos de conducta; tampoco la actividad judicial de los tribunales, ni los principios no escritos que para el iusnaturalismo racionalista constituyen el objeto central de los estudios jurídicos. 
Millas, siguiendo a Kelsen ${ }^{3}$, sostendrá que el verdadero objeto de la ciencia jurídica está constituido por la norma válidamente promulgada y eficazmente cumplida en el seno de una sociedad, conforme al amparo que le brinda la coacción estatal. Ahí debe, pues, el jurista, fijar su primer blanco de estudio. Pero, sería un error quedarse en la norma en cuanto mero enunciado lingüístico que manda, prohíbe o permite. Lo que el jurista siempre hace, dice Millas, es tratar de encontrar el auténtico sentido de la norma. Y el sentido trasciende la norma, pertenece, más bien, a las proposiciones o enunciados lógico-semánticos que conllevan las normas. Estos sentidos o significaciones, que pueden ser entendidos como sinónimos, son de carácter ideal y el sujeto cognoscente los capta intuitivamente mediante una intuición específica, intuición de esencias o intuición eidética.

Por tanto, la esencia del derecho consiste en idealidades (la significación de las proposiciones contenidas en las normas), y la tarea del jurista es aplicarse a la comprensión profunda de estas significaciones para resolver adecuadamente (con verdad y justicia) los conflictos o entuertos reales que acontecen en el seno de la sociedad. Como se puede ver, la relación, entonces, entre ciencias jurídicas en el sentido que las concibe Millas, y filosofía del derecho, es intrínsecamente estrecha, ya que el filósofo, en su tarea filosófica, no hace sino en general, lo que el científico del derecho realiza en las esferas de su conocimiento específico, esto es, en ambos casos, buscar el sentido último de las proposiciones jurídicas y aplicarlos, sea para resolver problemas concretos de la realidad social, sea para comprender el fenómeno jurídico y la realidad jurídica en sus últimos y definitivos determinantes gnoseológicos, metafísicos $\mathrm{y}$, sobre todo para Millas, axiológicos.

\section{Ser y deber ser como categorías supremas. Apriorismo kantiano}

Para Millas, el conocimiento de la realidad es posible por la ordenación de la experiencia recibída en ciertas categorías del entendimiento. Aunque no cita cuáles serían tales, sí expresa cuáles serían las supremas: las de "ser" y las de "deber ser".

Así, entonces, expresa, existen "ciertos esquemas básicos con que el propio entendimiento ordena la experiencia en su búsqueda de un saber total. La experiencia, en efecto, apenas considerada bajo la idea de su integración y unidad, se ordena según dos categorías de suprema generalidad: la del ser y la del deber ser, tan universales, que nada hay intuible o concebible, real o imaginario, actual o posible, fuera de ellas" (Millas 2012, I. 5).Vale decir, la experiencia, de suyo desorganizada, es ordenada por el sujeto según ciertas categorías, de las cuales las dos supremas son las del deber ser y

3 Millas tiene presente en especial la traducción de Moisés Nilve de la Teoría Pura del Derecho. Cfr. Kelsen 1973. Igualmente cita con frecuencia la Teoría General del Estado y del Derecho, en la traducción de García Máynez. Cfr. Kelsen 1969. 
ser. Aunque no son susceptibles de definición, por ser conceptos últimos, sin embargo su significado es preciso: ambos conceptos desempeñan una función tan importante en la organización y en la expresión de nuestro pensamiento que operamos siempre del modo más inequívoco con ellos. Por todo lo anterior, "ser" y "deber ser" no se abstraen de la realidad: son aportados por el sujeto para pensarla.

Ahora bien, entre ambos conceptos, el de ser tiene cierta prioridad, por cuanto funda al de deber ser. El deber ser tiene, por lo pronto, ser; es algo, escribe Millas, "de otra manera no podría siquiera ser concebido ni nada podríamos decir de él. Se trata, por lo tanto, de una idea fundada en el concepto de ser, pero a diferencia del ser puro y simple, del ser que es, el deber ser representa una exigencia de estimación o preferencia, un requerimiento de realidad que fuerza de una manera característica la conducta del hombre" (Millas 2012, II. 5). Así, el concepto del deber ser constituye una manera peculiar de pensar la idea de ser.

\section{La esencia del derecho. Intuicionismo husserliano}

Los conceptos de ser y deber ser ordenan la experiencia. También existen otros, fundados en éstos. Uno de ellos es el concepto de "derecho". Así, "el del derecho es solo el primero de todo un complejo sistema de conceptos esenciales o a priori que constituyen la estructura real del mundo jurídico y posibilitan lógicamente (no factualmente) su existencia", sostiene Millas (Millas 2012, III. 12). El concepto de "derecho" no se extrae de la realidad: lo aporta el sujeto para ordenar los datos de la experiencia, idea, como se ve, enteramente kantiana. El particular apriorismo de Millas queda claro en el siguiente texto: "la esencia del Derecho, como toda esencia, es fija, cerrada, finita: constituye una estructura estática. La experiencia es, en cambio, inestable, abierta, infinita; hay siempre una nueva experiencia posible. Siendo así, la esencia no puede determinarse por la experiencia: es inconmensurable. Mientras que la experiencia del Derecho va haciéndose, la idea del Derecho ya está hecha, es una misma; es, en este sentido, menos rica que la experiencia. Si hubiéramos de determinar la esencia de lo jurídico según parece realizada en la experiencia, nunca llegaríamos a conseguirlo, jamás podríamos conferir un sentido al vocablo Derecho, porque cabría esperar nuevas experiencias capaces de modificar ese sentido. El método inductivo se halla en este punto excluido de la investigación iusfilosófica" (Millas 2012, IV. 2). La esencia del derecho es captada mediante "intuición": de Kant asume Millas que la experiencia es ordenada por conceptos a priori; de Husserl, que algunos de tales conceptos son objeto de una intuición eidética. Esa intuición de esencia se da al captar al menos un caso singular del sistema jurídico o, incluso, al imaginar alguno. Puede decirse, entonces, que la esencia tiene prioridad lógica sobre la realidad, que es la condición de su comprensión y de su posibilidad.

$\mathrm{Si}$ analizamos la esencia de derecho "intuida", captaremos que el derecho es un sistema de normas. Una norma, para Millas, es una proposición prescriptiva que "mienta una cierta coordinación de posibilidades [de conducta] bajo la categoría del 
deber ser" (Millas 2012, V. 3). Se trata de un pensamiento no asertivo, de ahí que, siguiendo la más estricta ortodoxia kelseniana, sostenga Millas que "la norma expresa un deber ser y, como tal, no es verdadera ni falsa: solo puede ser justa o injusta, legítima o ilegítima" (Millas 2012, III. 4). Lo que sí puede ser verdadero o falso es la proposición descriptiva de la norma.

\section{La norma jurídica y el deber ser jurídico}

Normas hay de muchos tipos: prácticas, de trato social o de urbanidad, éticas, técnicas y jurídicas. ¿En qué se diferencian? En los valores en los que descansan: las prácticas se fundan en los valores de la utilidad; las de trato social, en los valores de decencia, elegancia, cortesía, galantería, respeto, delicadeza; las éticas, en valores como honradez, lealtad, generosidad, gratitud, sinceridad y compasión, es decir, en valores morales. De ahí que estas normas puedan llamarse "juicios normativos de valor", porque fundan su prescripción en la exigibilidad de un valor específico. Sin valor, no hay norma.

¿Y qué sucede con las normas jurídicas? ¿Cuál es el valor en el que se funda la norma jurídica?

Millas sostendrá que, en este caso, la situación es distinta. La norma jurídica no vale porque valga algún valor, no son juicios normativos de valor, aun cuando ambos declaren una exigencia de ser. Reconoce que como toda norma, de algún modo, la norma jurídica se refiere a valores, en cuanto no hay norma alguna que no se justifique en atención a un fin: "toda norma, en cuanto prescribe modos determinados de comportamiento, es una técnica para la consecución de ciertos fines, para la realización de determinados valores, pero independientemente de esto, se plantea la cuestión de si tales normas [las jurídicas] son en sí mismas prescriptivas de valores, si lo que las hace normativas es precisamente declarar la validez de un valor" (Millas 2012, V. 13).

La respuesta es negativa, como hemos visto: a diferencia de las otras normas, que valen porque vale un valor, las normas jurídicas valen con independencia de su realización de cualquier valor concreto. Ello, por cuanto "mientras nos limitemos a considerar únicamente lo que se da en la norma jurídica en cuanto tal, no podemos decir que intuyamos en ella misma ninguna exigencia ideal de preferencia, ninguna forzosidad estimativa; tampoco podemos decir que su carácter prescriptivo se altere o extinga al prescindir del aspecto valorativo. Mientras nos mantengamos dentro de la significación estrictamente jurídica de la norma, será inútil que apuremos su sentido para que salga de él una exigencia de valoración" (Millas 2012, V. 13). No "intuimos" que el comportamiento antijurídico sea, en tanto antijurídico, inmoral o disvalioso. Una norma que prescribe una conducta no la declara valiosa; la que prohíbe otra, tampoco la declara disvaliosa. Ni siquiera las normas del derecho penal imputan valor o disvalor a los actos que prohíben, como hemos dicho.

Más aún: Millas se esfuerza en probar mediante una técnica fenomenológica que, efectivamente, no hay nada en común entre la norma jurídica y la norma moral. 
Para ello toma un caso que trae Husserl en su "Lógica"4 con el objeto de demostrar que los enunciados normativos pueden desaparecer, salva veritate, a favor de enunciados puramente descriptivos, con lo cual quiere probar que la teoría pura de la ciencia, que él llama "Lógica", es la fuente de todo sistema normativo. El caso es el siguiente. Examinemos un enunciado de carácter normativo:

"Un guerrero debe ser valiente".

¿Será posible, pregunta, eliminar la cópula deóntica a favor de una noción axiológica descriptiva? Husserl sostiene que es posible y propone en reemplazo de la norma precedente la siguiente norma moral:

"Solo un guerrero valiente es un buen guerrero" (enunciado descriptivo).

Según él, todo el contenido semántico que hay en el primer enunciado se mantiene en el segundo pero, con la diferencia que el segundo es descriptivo y el primero, prescriptivo. La transformación demuestra, además, que la cópula deber ser expresa una exigencia axiológica de quien enuncia. Se quiere y se estima valioso que un guerrero sea valiente, es decir, es bueno que un guerrero sea valiente y malo que no lo sea.

En cambio, cree Millas, si tomamos, por ejemplo, una norma jurídica, de un código penal imaginario que rezare: "el asesino recibirá pena de prisión de por vida", y le aplicamos el examen precedente, sus resultados serán muy distintos. La norma legal no dice, ni directa ni indirectamente, que sea malo matar, que sea moralmente censurable. Solo dice secamente: "nadie mate, y si alguien mata reciba prisión de por vida". Eso dice y nada más. Luego, tendría razón Kelsen cuando sostiene que la norma jurídica bien entendida es "químicamente" pura, solamente establece una relación lógica entre un antecedente y un consecuente jurídico, haciendo de la conducta prohibída el antecedente necesario de una imputación de consecuencias.

Todavía más: "si se identifican las normas jurídicas con las otras normas de conducta, habrá de buscarse la diferencia entre ellas en el tipo de valor al cual se orientan, en los fines a que sirven. Y de esta manera se viene a incurrir en el error lógico de definir las cosas no en función de sus esencias, de la estructura lógica que las determina, sino en función de algo exterior a ellas: sus fines", dice Millas (Millas 2012, V. 13). De ahí que sean fútiles los intentos de definir la ley por su orden al bien común: si definimos la norma de derecho como una prescripción que rige las relaciones humanas en orden al bien común, nos encontramos nuevamente con una fórmula que realmente no define, "si por definición hemos de entender la conceptualización del qué es; el quid de las cosas. Tanto nos enteramos por ella de lo que es la norma jurídica, como nos enteramos de lo que es el ala si decimos simplemente 'es algo que sirve para volar"” (Millas 2012, V. 12), sostiene Millas. 
Todo lo anterior no significa, por supuesto, que Millas no valore que las normas jurídicas en particular y el orden jurídico en su totalidad se adecúen a los requerimientos de las normas morales. Es deseable que lo hagan, pero no le es esencial.

¿Qué es una norma jurídica? Para Kelsen, es una relación lógica entre un antecedente y un consecuente. Su forma lógica sería "si $A$ es, debe ser $B$ ". Su destinatario real es el juez. De tal norma, en sentido estricto, "primaria", por su rol principal, sostiene el jurista vienés que puede deducirse una norma "secundaria", dirigida al común de la población, que ordena la conducta contraria a la descrita como supuesto de hecho en el antecedente de la primaria. Así, una norma primaria sería "si alguien se apropia de cosa mueble ajena, sin la voluntad de su dueño y con ánimo de lucro, debe ser castigado con tal pena", y la secundaria, "no se debe hurtar, bajo tal pena".

Millas valora el reconocimiento del carácter hipotético de la norma jurídica por parte de Kelsen, pero no acepta su doctrina de que la "verdadera" norma se dirija únicamente al juez, y no al común de la población. Sucede, piensa, que dada la norma primaria, con ella, como parte suya, se da también la norma secundaria. De ahí que, más bien, haya que ver en la norma jurídica "un complejo normativo constituido por la prescripción de una conducta principal (norma secundaria) de hacer o no hacer algo y, la prescripción de una conducta consecuencial que manda realizar ciertos efectos para el caso de transgresión (norma primaria)" (Millas 2012, VI. 7). Así, la norma jurídica es un juicio hipotético conjuntivo, cuya estructura sería la siguiente: "si ' $A$ ' es, debe ser ' $B$ ' y, si 'no- $B$ ' es, debe ser ' $S$ '”. Por ejemplo, la norma que prohíbe renunciar los derechos laborales, enunciada de este modo en el artículo 5 inciso $2^{\circ}$ del Código del Trabajo: "los derechos establecidos por las leyes laborales son irrenunciables, mientras subsista el contrato de trabajo", expresaría el siguiente complejo proposicional normativo: "Si se tiene un derecho ( $\mathrm{Si}$ ' $A$ ' es) no debe renunciarse (' $B$ ' debe ser) y, si se renuncia el derecho (si no '- $B$ ' es) tal renuncia debe ser nula (debe ser ' $S$ ')”. En consecuencia, toda norma jurídica incluye en su estructura una sanción.

Si la norma jurídica, así entendida, no tiene por qué necesariamente ser justa, se sigue que su obligatoriedad no depende de su capacidad de obligar en conciencia. Así, frente a Ivan Hübner ${ }^{5}$, que sostenía tal, expresa que "la obligatoriedad de la norma es autárquica, esto es, existe aunque yo no me sienta en conciencia obligado" (Millas 2012, VII. 4). Lo cual no impide, obviamente, que la norma jurídica pueda obligar en conciencia en cuanto realiza o protege ciertos valores.

Y, si todo es así: ¿cómo podemos explicar la fuente de validez de las normas jurídicas? Kelsen diría que el origen de su validez reside en otra norma que regula su producción. Siguiendo a Kelsen, Millas sostiene que la validez de una norma jurídica está dada por haber sido producida de acuerdo al procedimiento establecido por una norma superior. El derecho, así, es una unidad perfectamente cerrada: "el derecho crea el derecho, hemos visto; la norma inferior no hace sino aplicar la norma superior, aplicación y creación del derecho son una misma cosa" (Millas 2012, VII. 6). En otras 
palabras, la validez a una norma le es otorgada por una norma superior. ¿Y qué ocurre en el caso de la Constitución, norma cúspide del sistema?

Tres respuestas se han dado, nos dice Millas: las metafísicas o trascendentalistas, empiristas y, lógico-formal o inmanentistas. Según la primera, propia de los diversos iusnaturalismos, "la validez jurídica se funda en la obligatoriedad de conciencia de ciertos preceptos trascendentales al Derecho y dotados de valor intrínseco" (Millas 2012, VII. 6). Debe rechazarse tal tipo de respuesta, porque confunde la validez axiológica y la jurídica: la validez de una norma deriva de otra norma anterior; la axiológica, del contenido de lo valorado, concluye Millas.

Deben rechazarse, asimismo, las respuestas empiristas, propias de los diversos realismos jurídicos, porque ilegítimamente concluyen la validez de una instancia de la existencia de hechos, lo cual implica un falacioso tránsito del ser al deber ser: “del hecho del poder, por ejemplo, puede resultar el hecho de la obediencia, pero no la norma de que se deba obedecer. Las normas no son meros hechos" (Millas 2012, VII. 6), sostiene.

La tercera respuesta es muy conocida y se debe a Kelsen: es necesario postular una norma fundamental del sistema, que le otorgue validez a la Constitución. Tal norma no es norma positiva, porque no ha sido puesta, sino que es supuesta. Es, en realidad, un "presupuesto gnoseológico", una "hipótesis necesaria para el conocimiento de las relaciones subsecuentes de validez entre las normas positivas del orden jurídico" (Millas 2012, VII. 6), por ende, una categoría formal del conocimiento jurídico. Un concepto a priori en la mente del jurista destinado a producir el conocimiento jurídico. Es, en síntesis, la condición posibilitante del pensamiento jurídico. Por ser a priori es formal. De ahí que no exija de los órdenes jurídicos particulares ningún contenido concreto.

Al no depender su validez de otro sistema normativo, el orden jurídico es así autárquico. Eso sí, aunque no dependa en su validez de otros órdenes normativos, el sistema jurídico debe, en su conjunto, ser eficaz para ser válido. No se trata de que la eficacia sea sinónimo de validez, sino más bien condición real de ella. Ello no acontece en el caso de las normas consideradas individualmente: ellas son válidas por el solo hecho de haber sido producidas de acuerdo a lo prescrito por una norma superior, aun cuando no sean eficaces. La eficacia de una norma consiste en "su grado de cumplimiento, es el grado de correspondencia entre la conducta requerida y la conducta realizada: una norma válida puede o no ser eficaz según que el comportamiento real de las gentes corresponda o no a la conducta por ella prescrita. Representa, de este modo, una conexión entre los dominios del ser y del deber ser", asegura Millas (Millas 2012, VII. 8).

\section{El fundamento del derecho}

Con todo, podría alguien preguntarse, “¿por qué debo yo obedecer esta norma?”. Un positivista ortodoxo como Kelsen respondería: "porque ha sido producida conforme a lo prescrito por una norma superior" (lo que a su vez lleva a un regreso al infinito porque 
a su turno esa norma superior debió producirse por otra norma igualmente superior $)^{6}$. De ese modo podríamos llegar a la primera constitución histórica, y preguntarnos nuevamente, “¿por qué debemos obedecerla?”. Kelsen no podría dar ninguna respuesta a tal pregunta. La única que podría dar sería: "porque así lo expresa la norma fundamental, la cual tiene validez hipotética, no vale por promover ningún valor, y además es una simple condición de posibilidad del conocimiento jurídico". Esta respuesta carece de fuerza de convicción.

Millas está consciente de lo anterior, y su originalidad frente a Kelsen radica en que, habiendo asumido los presupuestos de la teoría pura del derecho, ha llegado más allá del positivismo kelseniano al reconocer un fundamento extrajurídico al derecho como un todo.

Por tanto, la pregunta “¿por qué debemos obedecer esta norma?”, la reconduce Millas a la siguiente: “¿por qué debo obedecer el derecho?”. Su respuesta es clara: se debe obedecer al derecho porque éste es un bien. En efecto, aunque toda norma jurídica, aisladamente considerada sea axiológicamente neutral, el todo del sistema jurídico, incluyendo la norma categorial, no lo es. Tal todo requiere un fundamento: "podemos aceptar que cada norma obligue porque, en última instancia, obliga la totalidad del orden jurídico, pero la razón de la obligatoriedad del orden jurídico mismo ya no puede ser jurídica y lo trasciende: el Derecho no puede fundar su propio deber ser" (Millas 2012, IX. 4) ${ }^{7}$. Así, frente a Kelsen, que cerraba la cadena de fundamentaciones de las normas jurídicas con la norma fundamental, Millas hará ver la necesidad de recurrir a un imperativo axiológico para justificar la obligatoriedad del derecho. Pero, a diferencia de los iusnaturalistas tradicionales, aceptará que el fundamento de validez de las normas jurídicas solo puede radicar en otra norma jurídica, siendo la última de éstas una norma supuesta que actúa como mediadora entre el imperativo axiológico y las normas jurídicas, transformando al conjunto de éstas en un sistema.

"El derecho es un bien”, dice Millas. ¿Qué es un bien? Una entidad que realiza un valor, la concreción de un valor, una cosa valiosa. Y un valor es, nos dice, un objeto ideal, los valores son "posibilidades de ser (esencias) que se dan a la conciencia con la exigencia de ser realizados y estimados" (Millas 2012, IX. 3). Los valores, aunque no existentes en el tiempo y espacio -a diferencia de los bienes, que sí existen espaciotemporalmente-, son realmente, aunque su ser es ideal ${ }^{8}$. Por ello, no están sujetos a las relaciones causales a las que están sujetos los entes reales, "existentes", como dice Millas. Por todo ello, su ser se nos aparece como extraño. En síntesis, los entes ideales "no duran, no crecen, no nacen ni se extinguen, no tienen cualidades físicas ni

Hoy día uno de los debates más intensos que se libra entre filósofos y teóricos del derecho es el relativo a la validez material del derecho. Es decir, no bastaría, como sostiene el positivismo, con la validez formal para dar por válido un sistema jurídico.

También desarrolla esta idea Millas en Millas 1956.

8 Cfr. Millán-Puelles 1947. Millas también desarrolla su teoría axiológica en Millas 1969. 
psíquicas, no están ligados por relaciones causales, no se engendran ni modifican entre sí y, no obstante, poseen ser, son algo, puesto que pueden ser pensados" (Millas 2012, $X .2$ ). Aunque esto pudiera parecer platonismo puro, es en realidad la fenomenología alemana de los valores la que de modo manifiesto influye en nuestro iusfilósofo, a tal punto que puede decir que la Antigüedad greco-romana, la Edad Media y Moderna ignoran el problema de los valores en cuanto tales. Los valores no son ni las formas (eidê) platónicas, ni el bien aristotélico ni su sucesor, el bonum trascendental medieval. Pero no son realidades disponibles por el sujeto. Se le imponen a él. Millas llega a reconocer la posibilidad de su jerarquización -aunque rechace la propuesta de Scheler.

¿Cómo se conocen los valores? La respuesta es la propia de todo fenomenólogo: por intuición intelectual, tal como se conocen todos los entes ideales. El entendimiento humano es la facultad de captación de los valores y, precisamente porque son a priori, como todo ente ideal. "Todas las esencias poseen cualidades específicas que el entendimiento aprehende con evidencia" (Millas 2012, X. 4). Aunque su aprioridad solo tiene sentido como capacidad de organización de la experiencia. Los valores mismos, dirá Millas, "son las formas ideales que posibilitan la realidad concreta y la hacen inteligible" (Millas 2012, X. 4). La herencia kantiana no se pierde nunca.

Ahora bien: si el derecho es un bien con propensión a concretar un valor, ¿cuál será éste? Preguntar tal cosa es preguntar por el fin del derecho. Pregunta prohibída por la "Teoría Pura del Derecho", que Millas intenta responder por considerarla no solo existencialmente relevante, sino también propia de la filosofía jurídica. Y ello simplemente porque, "si el Derecho es -como Kelsen lo ha reconocido expresamente'una técnica social específica', solo puede ser exhaustivamente comprendido en función de su específica finalidad. La de un medio solo puede comprenderse a la luz de sus fines" (Millas 2012, X. 5).

Es claro que lo que sea la "finalidad específica" del derecho ha sido objeto de discusión a lo largo de la historia de la filosofía jurídica. Multiplicidad de valores han sido propuestos como candidatos al título de constitutivo de la finalidad del derecho: justicia, seguridad, paz, por citar solo los más conocidos. Y Millas reconocerá que el Derecho puede servir a todos ellos y, más aún, a todo valor posible, incluso a aquellos aparentemente tan ajenos a él como la belleza o la verdad. Y es que el derecho muestra una "plasticidad axiológica": sirve para posibilitar la concreción de multiplicidad de valores o, por decirlo con Millas, tal plasticidad consiste en que "se halle en conexión con todos los valores y que en cualquiera de ellos podamos reconocer un valor fundamental del Derecho" (Millas 2012, X. 7). Todos los valores: desde la salud, valor biológico, hasta el altísimo de la verdad. De ahí que el derecho, siendo un medio, no es un medio cualquiera, como podría serlo una máquina, o una herramienta: tiene una particular dignidad, su rango es de lo más alto entre los bienes instrumentales del hombre.

El derecho puede servir a todos los valores y, sin embargo, expresa Millas, no todos ellos constituyen su finalidad específica. Ni la verdad, ni la belleza, ni la honestidad, ni la salud, ni la libertad, ni aún la justicia, nos dirá Millas, constituyen su télos propio. Tales valores son, más bien, aunque parezca extraño tras todo lo dicho, solo fines accidentales al derecho. No la paz, porque, nos expresa nuestro autor, la paz es una 
esencia intuible separadamente del derecho, aunque el derecho sea un buen instrumento para realizarla en nuestra realidad social. Tampoco, nos dirá, la justicia -aunque reconociendo que la situación de ésta es peculiarísima en la investigación iusfilosófica, que no es un valor jurídico por la misma razón: "ni su esencia, ni su efectiva realidad se hayan inexorablemente ligadas, en principio, al Derecho. El Derecho contribuye a realizarla, puede ser incluso la condición de hecho necesaria para que haya justicia entre los hombres, pero su idea, la posibilidad de vida que involucra, no contiene la idea de vida jurídica como ingrediente esencial" (Millas 2012, X. 11).

El único valor esencialmente jurídico, nos dirá Millas, es la seguridad jurídica. La razón es sencilla: es el único valor para la realización del cual el derecho es, a la vez, condición necesaria y suficiente. La seguridad jurídica no consiste en una simple tranquilidad o paz social. Consiste en "la situación del individuo como sujeto activo y pasivo de relaciones sociales cuando, sabiendo o pudiendo saber cuáles son las normas jurídicas vigentes, tiene fundamentadas expectativas que ellas se cumplan" (Millas 2012, X. 11). Incluye así dos elementos: conocimiento de las normas jurídicas, y predictibilidad del comportamiento del resto de los hombres. Esta seguridad es así "una dimensión ontológica del Derecho, su fin a priori, al cual todo otro fin queda funcionalmente supeditado" (Millas 2012, X. 8). Esto debe entenderse bien: no como que la seguridad jurídica sea superior a otros valores, como la justicia. Ella misma se orienta a otros valores. Quiere decir que la seguridad jurídica es condición de la realización de otros valores: "el orden jurídico antepone la seguridad a todo otro valor como un medio para favorecer el imperio de todos los valores" (Millas 2012, X. 13). La seguridad no es un fin en sí mismo. Por ello, la obediencia al derecho no viene prescrita por un imperativo categórico, sino por uno hipotético.

\section{De nuevo sobre la norma jurídica}

A continuación haremos una breve consideración crítica sobre la noción de norma jurídica en Millas. Nos parece que, dadas las premisas puestas por el iusfilósofo, debió haber concluido que la obligatoriedad de toda norma le viene de su fin, que toda norma se orienta a un fin que la fundamenta.

En efecto, ¿puede sostenerse que el derecho es un bien y sirve a un valor, y las normas no? Cuando Millas dice que el derecho es un bien, está tratando de justificar su existencia. Volvamos nuevamente a la pregunta que imaginariamente hacíamos a Kelsen: “¿por qué debo obedecer esta norma?”. Vimos que éste no podía dar una respuesta satisfactoria. No se nos puede responder, "porque así lo expresa la norma fundamental, la cual tiene validez hipotética, aunque no valga por promover ningún valor, y además es condición de posibilidad del conocimiento jurídico". Es evidente que esa respuesta no nos da ningún motivo para obedecer: no nos da razón para la acción. Y lo propio de las normas jurídicas es ser razones para actuar (Hart, Raz). Si se nos responde, en cambio, como podría hacerlo Millas, "porque sirve a la seguridad, y 
ésta es un valor", sí se nos da una respuesta que justifica nuestra acción. Si ello es así, entonces la noción de seguridad entra en la definición de norma jurídica, por cuanto la norma sería un instrumento para proteger tal seguridad. Por ende, del reconocimiento del derecho como un bien o sirviendo al valor de la seguridad se sigue una definición "extrínseca" de la norma, que es lo que Millas niega y, por ende, la norma sí expresa un valor, y llama disvalioso al comportamiento que atenta contra ella: lo llama disvalioso por atentar contra la seguridad. En otras palabras: la norma no es razón para actuar si no sirve a un bien/valor, pero las normas son razones para actuar, por ende, la referencia al valor entra en la definición de norma.

Se podría, tal vez, contra-argumentar del modo siguiente: del hecho de que el derecho tienda como un todo a afianzar la seguridad, no se sigue que las normas individuales lo hagan. Éstas pueden tener otras funciones. Las funciones de las normas del derecho privado son regular los tratos patrimoniales entre privados. Trabajemos con una metáfora deportiva. Un equipo de fútbol tiene como finalidad ganar el partido (meter la mayor cantidad de goles en el arco contrario, evitando los goles en el propio). De ahí no se sigue que cada jugador tenga como finalidad ganar el partido. El defensa, en cuanto defensa, tiene como función detener a los delanteros, el delantero, meter goles, el arquero, atajar, etc.

Sin embargo, en realidad no se entiende qué es el "atajar", sino como parte de un juego que consiste en meter la mayor cantidad de goles en el arco contrario evitando los goles en el arco propio. Es decir, no se entiende lo que es "arquero" sin comprender el fin que persigue el equipo. Del mismo modo, si la función del derecho como conjunto es afianzar la seguridad, entonces no se entiende la función de las partes sino como contribución a ese fin. ¿Se puede entender la función del arquero sin entender la del equipo? ¿Qué pasaría si, enfrentado a alguien que no conoce el fútbol en absoluto, y que preguntase qué es "arquero", le dijésemos: "es el jugador que puede ocupar las manos y debe atajar los tiros que vayan a su arco"? ¿Nos estaríamos dando a entender? Pareciera que del reconocimiento del derecho como un bien, se sigue una definición extrínseca de norma. El arquero, en cuanto arquero, no tiene como función ganar el partido, sino atajar; en cuanto jugador, tiene como función contribuir a ganar el partido. La norma de derecho civil, en cuanto norma de derecho civil, no tiene como función servir la seguridad; pero en cuanto norma jurídica, sí.

Construyamos otra analogía, a fin de aclarar nuestra idea: supongamos que el fin del hombre fuese la subsistencia (algo análogo al fin que Jorge Millas pone como fin específico del derecho). Ello solo puede hacerlo si los órganos que tiene tienden a tal fin, cumplen alguna función que, en conjunto con la función de los demás, asegura tal subsistencia. En tal caso, aunque la función del corazón sea bombear sangre, no se entiende adecuadamente sino como contribución al fin del todo que es la subsistencia. Y ello es así puesto que si un órgano no cumple función alguna en tal sentido, función que sirva al fin que ex hypothesi hemos puesto para el todo, la subsistencia, no es órgano, aunque tenga apariencia de tal. Por eso podemos extirparlo, sin que el todo sufra menoscabo alguno. ¿Es realmente el apéndice un órgano? ¿Es un lunar un órgano? ¿Es el granuloma que se forma cuando se encarna una uña, un órgano? Es obvio que 
no. ¿Por qué? Porque no favorece el fin del todo9. Podemos llamarlo, por supuesto, "órgano", porque se asemeja a, porque se encuentra incrustado en el todo orgánico, pero realmente no lo es. Tal acontece con una "norma" que no tienda a asegurar el fin que ex hypothesi se ha puesto al todo del orden jurídico. Ello no implica, por supuesto, que tal "norma" haya de ser desobedecida o ignorada necesariamente, lo mismo que el reconocimiento del carácter no orgánico de las cosas que llamamos "apéndice" o "lunar" no implica que deban ser extirpados del todo orgánico en el que inhieren.

Más aún: si la norma jurídica no incluyese en su definición referencia a valor alguno, sino que se la diferenciase de otras normas simplemente por imputar consecuencias, siendo su forma lógica "Si $A$ es, $B$ debe ser; y si no es $A$, debe ser $S$ ", entonces no existe modo de diferenciarlas de las normas de los juegos. Podemos decir, perfectamente, que la norma del fútbol que impide el "offside" imputa consecuencias, y no intuimos en ella, aparentemente, valor alguno, siendo su forma, "Si un jugador va a dar un pase a otro, debe encontrarse este último habilitado por un defensa, y si no es así, el juez debe cobrar falta". ¿No sería ésta, en consecuencia, también una norma jurídica? Es tan eficaz como la ley del tránsito. Puede usarse de ejemplo las reglas de cualquier otro juego. O las que rigen en una clase: "Si el alumno rinde una prueba, debe no copiar, y si copia, el profesor debe sancionarlo con un 1". ¿También es norma jurídica? [y, en caso de no serlo, de dónde deriva la validez de tales normas? ¿De una norma fundamental que ordena obedecer lo que diga la FIFA?]. Nos parece claro que no son normas jurídicas pero, ¿cómo podrían diferenciarse de las jurídicas, si tienen la misma estructura que Millas asigna a éstas, y ambas parecen no tender a valor alguno (al menos las del juego)? Realmente, solo se pueden diferenciar si entendemos que tienden, en conjunto con otras de su tipo, a asegurar un valor determinado.

Con esto, llegamos a un punto que solo queremos dejar planteado. Jorge Millas expone que el único valor específicamente jurídico es la seguridad jurídica. Sin embargo, él mismo reconoce que tal valor se subordina a otros valores. No pretende en modo alguno decir que la seguridad jurídica sea el supremo valor social. Se encuentra lejos de lo que Bobbio llama "positivismo ideológico". En otras palabras: la seguridad jurídica no otorga un fundamento suficiente a la obligatoriedad de las normas. Ella misma requiere cierto fundamento posterior. Lo anterior parece bastante claro: el condenado a muerte prefiere cierta incerteza a la certeza de la ejecución de su condena. ¿Puede encontrarse un fundamento tal a la obligatoriedad de la norma que incluso un condenado a muerte prefiera obedecerla antes que desobedecerla (véase el comportamiento de Sócrates en el "Critón”, y Sócrates fue condenado injustamente)? Tal sería un fundamento absoluto. Millas no se explaya sobre el tema. ¿Puede la multiplicidad de valores a los cuales sirve

$9 \quad$ Cfr., en el mismo sentido, Aristóteles, Política III, 4, 1276b22-28: “Aunque los marinos son desiguales en cuanto a su función (uno es remero, otro piloto, otro vigía y otro tiene otra denominación semejante), es evidente que la definición más exacta de cada uno será propia de su función, pero al mismo tiempo una cierta definición común se adaptará a todos. La seguridad de la navegación es, en efecto, obra de todos ellos, pues a este fin aspira cada uno de los marinos". 
el derecho proveer tal fundamento? ¿Y si tales valores entran en colisión entre sí? Tal vez la respuesta esté en la referencia a aquél otro valor que Millas mismo reconoce como una "situación peculiarísima en la investigación iusfilosófica": la justicia.

\section{Comentarios finales}

Millas, entonces, rechaza, en última instancia, el formalismo kelseniano, en lo relativo a la fundamentación del derecho en general. No es cuestión de mera forma, un sistema jurídico no se valida a sí mismo. Para validarlo hay que recurrir a ítems extrajurídicos. ¿Qué ítems son éstos? Cosas buenas, cosas valiosas. Luego y finalmente, los valores son el fundamento y la razón última de validez del derecho.

Lo sorprendente de esta conclusión de Millas, que compartimos ampliamente, es que no se sigue, ni parece compatible con, su asunción de las creencias centrales de la "Teoría Pura". Es cierto que sería absurdo contribuir a fundar una axiología jurídica si, al mismo tiempo, se expulsan los valores en cuanto constantes internas del derecho. ¿Qué axiología sería esa! Millas observa con mirada social y moral y no puede dejar de ver cómo las cosas efectivamente son. Pero, claro, no se puede servir a dos señores. No es compatible asumir la teoría pura, con sus consecuencias antiaxiológicas y, al mismo tiempo, sostener y defender que el derecho es una cosa valiosa tanto en sí mismo, como por el rol finalista que persigue. Uno puede preguntarse: ¿pero de dónde extrae el derecho su fuerza intrínsecamente valiosa, si sus normas tomadas individualmente o por grupos no muestran trazas de valor?

Claro que Millas podría contestar que una cosa es el ordenamiento jurídico (la totalidad de las normas vigentes) de una nación, y otra el derecho de esa nación. Y podría decir que el derecho es más que el conjunto de las norma positivas en tanto implica también principios jurídicos y no jurídicos, valores, prácticas judiciales, etc. Pero así y todo, sigue siendo cierto que la norma jurídica individual sigue contribuyendo al fin del todo, que en este caso estaría constituido por normas y principios, y, en tal sentido, tiene carácter valioso por promover el fin específico del derecho que, según Millas, es la seguridad jurídica.

Seguramente si Millas hubiese vivido más, y hubiese asistido al debate contemporáneo de los filósofos y teóricos del derecho, habría terminado por abandonar el "paliopositivismo" kelseniano, que se levanta como un obstáculo para la constitución de una teoría jurídica compatible con lo que la lógica interna de su pensamiento lo conduce a construir.

\section{Referencias bibliográficas}

Alexy, Robert (1994), El Concepto y la Validez del Derecho. Traducción de Jorge Malem Seña. Barcelona: Gedisa. 
Aristóteles (2007), Política. Traducción de Manuela García Valdés. Madrid: Gredos. Hübner, Jorge Iván (1951), Introducción a la Teoría de la Norma Jurídica y la Teoría de la Institución. Santiago: Editorial Jurídica de Chile.

Husserl, Edmund (1982), Investigaciones Lógicas. Traducción de Manuel García Morente y José Gaos. Madrid: Alianza. 2 vols.

Kelsen, Hans (1969), Teoría General del Estado y del Derecho. Traducción de Eduardo García Máynez. México: UNAM.

(1973), Teoría Pura del Derecho. Traducción de Moisés Nilve. Buenos Aires: EUDEBA.

Millán-Puelles, Antonio (1947), El problema del ente ideal. Madrid: CSIC.

Millas Jorge (1956), "Fundamentos reales del orden lógico-formal del Derecho", Revista de Filosofia 3: 67-74.

(1969), Idea de la Filosofía. El conocimiento. Santiago: Editorial Universitaria. 2 vols.

(1982), "Los determinantes epistemológicos de la Teoría Pura del Derecho", Apreciación crítica de la Teoría Pura del Derecho. Valparaíso: Edeval; pp. 31-63.

(2012), Filosofia del Derecho. Santiago: Ediciones Universidad Diego Portales. 